\title{
U.S. State Life Tables, 2019
}

by Elizabeth Arias, Ph.D., Jiaquan Xu, M.D., Betzaida Tejada-Vera, M.S., and Brigham Bastian, B.S., Division of Vital Statistics

\section{Abstract}

Objectives-This report presents complete period life tables for each of the 50 states and the District of Columbia (D.C.) by sex based on age-specific death rates in 2019.

Methods-Data used to prepare the 2019 state-specific life tables include: 2019 final mortality statistics; July 1, 2019, population estimates based on the 2010 decennial census; and 2019 Medicare data for people aged 66-99. The methodology used to estimate the state-specific life tables is the same as that used to estimate the 2019 national life tables, with some modifications.

Results-Among the 50 states and D.C., Hawaii had the highest life expectancy at birth, 80.9 years in 2019, and Mississippi had the lowest, 74.4 years. Life expectancy at age 65 ranged from 17.5 years in Mississippi to 21.2 years in Hawaii. Life expectancy at birth was higher for females in all states and D.C. The difference in life expectancy between females and males ranged from 3.5 years in Utah to 6.4 years in Mississippi.

Keywords: state life expectancy • survival $\bullet$ death rates • National Vital Statistics System

\section{Introduction}

This report presents annual complete period life tables for each of the 50 states and the District of Columbia (D.C.) for 2019. Life tables were produced for the total, male, and female populations of each state and D.C. based on age-specific death rates for 2019. The methodology used to estimate the statespecific life tables is the same as that used to estimate the annual U.S. life tables (1), with some minor modifications described in the Technical Notes.

Life tables are of two types: the cohort (or generation) life table and the period (or current) life table. The cohort life table presents the mortality experience of a particular birth cohort-all people born in the year 1900, for example-from the moment of birth through consecutive ages in successive calendar years. Based on age-specific death rates observed through consecutive calendar years, the cohort life table reflects the mortality experience of an actual cohort from birth until no lives remain in the group. To prepare just a single complete cohort life table requires data over many years. Due to data unavailability or incompleteness (2), constructing cohort life tables based entirely on observed data for real cohorts is usually not feasible. For instance, a life table representation of the mortality experience of a cohort of people born in 1970 would require the use of data projection techniques to estimate deaths into the future $(3,4)$.

The period life table, by contrast, presents what would happen to a hypothetical cohort if it experienced throughout its entire life the mortality conditions of a particular period. For example, a period life table for 2019 assumes a hypothetical cohort that is subject throughout its lifetime to the age-specific death rates prevailing for the actual population in 2019. The period life table could be characterized as producing a snapshot of current mortality experience and showing the long-range implications of a set of age-specific death rates that prevailed in a given year. In this report, the term "life table" refers only to the period life table, not to the cohort life table.

Life tables can be classified in two ways according to the length of the age interval in which data are presented. A complete life table contains data for every single year of age. An abridged life table typically contains data by 5 - or 10 -year age intervals. A complete life table can be combined into 5- or 10-year age groups. U.S. decennial life tables and, beginning in 1997, U.S. annual life tables are complete life tables. This report presents the results for 2019 for the series of annual complete period state-specific life tables.

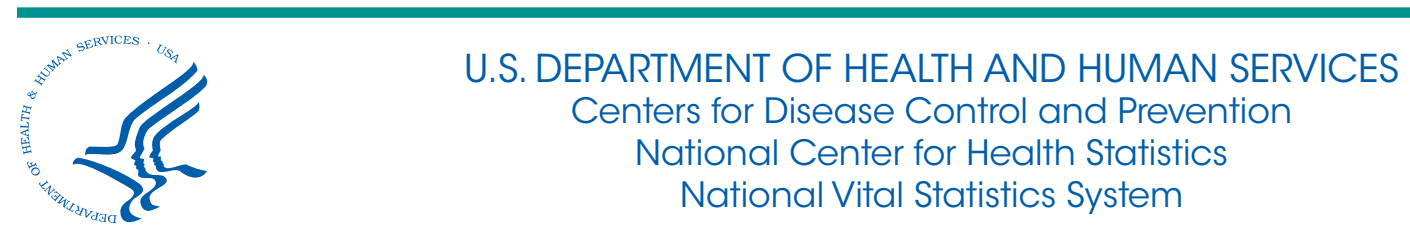




\section{Data and Methods}

The data used to prepare the U.S. state life tables for 2019 are state-specific final numbers of deaths for 2019; July 1, 2019, state-specific population estimates based on the 2010 decennial census; and state-specific death and population counts for Medicare beneficiaries aged 66-99 for 2019 from the Centers for Medicare \& Medicaid Services. Data from the Medicare program are used to supplement vital statistics and census data for ages 66 and over.

The methodology used to estimate the 2019 complete life tables for the 50 states and D.C. presented in this report is the same as that used to estimate the annual U.S. national life tables, with some modifications. For some states, very small agespecific or zero numbers of deaths in childhood ages sometimes required the use of additional smoothing techniques not needed in constructing the national life tables. A modification to the estimation of death rates in the oldest ages was also necessary because of the lack of state-specific census population estimates for ages 85-100. The methodology with modifications used to construct the first set of annual U.S. state life tables is detailed in the Technical Notes.

\section{Explanation of life table columns}

Column 1. Age (between $x$ and $x+1$ )-Shows the age interval between the two exact ages indicated. For instance, 20-21 means the 1-year interval between the 20th and 21st birthdays.

Column 2. Probability of dying $\left(q_{x}\right)$-Shows the probability of dying between ages $x$ and $x+1$. For example, for males who reach age 20 in Massachusetts, the probability of dying before reaching their 21st birthday is 0.000616 (Table MA-2). This column forms the basis of the life table; all subsequent columns are calculated from it.

Column 3. Number surviving $\left(I_{x}\right)$-Shows the number of people from the original hypothetical cohort of 100,000 live births who survive to the beginning of each age interval. The $I_{x}$ values are computed from the $q_{x}$ values, which are successively applied to the remainder of the original 100,000 people still alive at the beginning of each age interval. For example, out of 100,000 male babies born alive in Massachusetts in 2019, 99,215 will survive to their 21st birthday (Table MA-2).

Column 4. Number dying $\left(d_{x}\right)$-Shows the number dying in each successive age interval out of the original 100,000 live births. For example, out of 100,000 males born alive in Massachusetts in 2019, 61 will die between ages 20 and 21 (Table MA-2). Each figure in column 4 is the difference between two successive figures in column 3.

Column 5. Person-years lived $\left(L_{x}\right)$-Shows the number of person-years lived by the hypothetical life table cohort within an age interval $x$ to $x+1$. Each figure in column 5 represents the total time (in years) lived between two indicated birthdays by all those reaching the earlier birthday. Consequently, the figure 99,246 for males in the age interval $20-21$ is the total number of years lived between the 20th and 21st birthdays by the 99,277 males in Massachusetts (column 3) who reached their 20th birthday out of 100,000 males born alive (Table MA-2).
Column 6. Total number of person-years lived $\left(T_{x}\right)$-Shows the total number of person-years that would be lived after the beginning of the age interval $x$ to $x+1$ by the hypothetical life table cohort. For example, the figure $5,803,110$ is the total number of years lived after reaching age 20 by the 99,277 males reaching that age in Massachusetts (Table MA-2).

Column 7. Expectation of life $\left(e_{x}\right)$-At any given age, shows the average number of years remaining to be lived by those surviving to that age, based on a given set of agespecific rates of dying. It is calculated by dividing the total person-years that would be lived beyond age $x$ by the number of people who survived to that age interval $\left(T_{x} / I_{x}\right)$. Thus, the average remaining lifetime for males in Massachusetts who reach age 20 is 58.5 years $(5,803,110$ divided by 99,277$)$ (Table MA-2).

\section{Standard errors of the probability of dying and life expectancy}

Although based on complete counts of death, the life table functions presented in this report are subject to error. As a result, standard errors of the two most important functions, the probability of dying and life expectancy, are also presented. The mortality data on which state life tables are based are not affected by sampling error because they are based on complete counts of deaths and, as a result, standard errors reflect only stochastic (random) variation. While measurement errors such as age misreporting on death certificates or census data are known to affect mortality estimates, they are not considered in calculating the standard errors of the life table functions. In most cases, standard errors for life expectancy at birth and the probability of dying are small due to large numbers of deaths. However, for some states with small populations, particularly at the youngest ages, the standard errors presented are relatively large.

\section{Results}

\section{Complete life tables for the $\mathbf{5 0}$ states and D.C.}

A set of complete period life tables for each state and D.C. is available online from "U.S. State Life Tables, 2019" at: https://ftp.cdc.gov/pub/Health_Statistics/NCHS/Publications/ NVSR/70-18/. Table I lists table titles for each of these tables. Table numbering is based on the federal information processing standards, or FIPS, alphabetic code for the state combined with a table code. The table codes are 1 for the total population, 2 for males, 3 for females, and 4 for the standard errors of the probability of dying and life expectancy. For example, Table FL-2 refers to the complete period life table for males in Florida.

\section{Life expectancy in the $\mathbf{5 0}$ states and D.C.}

Table A shows life expectancy at birth for the total, male, and female populations for each state, D.C., and the United States. In 2019, among the 50 states and D.C., Hawaii ranked first for the total and female populations, with life expectancies at birth of 80.9 and 83.9 years, respectively. California ranked first for 
Table A. Life expectancy at birth, rank, and standard error, by sex: Each state, District of Columbia, and United States, 2019

\begin{tabular}{|c|c|c|c|c|c|c|c|c|c|}
\hline Area & Rank & Total & Standard error & Rank & Male & Standard error & Rank & Female & Standard error \\
\hline Hawaii & 1 & 80.9 & 0.119 & 5 & 78.0 & 0.172 & 1 & 83.9 & 0.158 \\
\hline California . & 2 & 80.9 & 0.022 & 1 & 78.4 & 0.032 & 2 & 83.3 & 0.028 \\
\hline New York. & 3 & 80.7 & 0.030 & 3 & 78.2 & 0.045 & 3 & 83.1 & 0.040 \\
\hline Minnesota & 4 & 80.4 & 0.056 & 2 & 78.3 & 0.082 & 6 & 82.6 & 0.075 \\
\hline Massachusetts. & 5 & 80.4 & 0.050 & 6 & 77.9 & 0.074 & 5 & 82.8 & 0.065 \\
\hline Connecticut ... & 6 & 80.3 & 0.073 & 9 & 77.7 & 0.107 & 4 & 82.8 & 0.094 \\
\hline New Jersey & 7 & 80.1 & 0.046 & 10 & 77.6 & 0.067 & 7 & 82.5 & 0.060 \\
\hline Washington ........... & 8 & 80.0 & 0.048 & 7 & 77.9 & 0.070 & 10 & 82.1 & 0.064 \\
\hline Colorado ............ & 9 & 80.0 & 0.058 & 8 & 77.8 & 0.084 & 9 & 82.2 & 0.077 \\
\hline Vermont. . & 10 & 79.8 & 0.172 & 13 & 77.2 & 0.259 & 8 & 82.3 & 0.223 \\
\hline Utah. . & 11 & 79.7 & 0.078 & 4 & 78.0 & 0.114 & 17 & 81.5 & 0.105 \\
\hline Oregon. . & 12 & 79.6 & 0.066 & 12 & 77.3 & 0.097 & 11 & 81.9 & 0.086 \\
\hline Idaho ... & 13 & 79.5 & 0.101 & 11 & 77.5 & 0.147 & 20 & 81.5 & 0.137 \\
\hline Rhode Island . & 14 & 79.5 & 0.135 & 17 & 77.0 & 0.199 & 12 & 81.8 & 0.179 \\
\hline New Hampshire & 15 & 79.4 & 0.116 & 15 & 77.1 & 0.171 & 14 & 81.6 & 0.154 \\
\hline Wisconsin .... & 16 & 79.3 & 0.057 & 16 & 77.0 & 0.082 & 18 & 81.5 & 0.078 \\
\hline Nebraska . . & 17 & 79.2 & 0.098 & 14 & 77.1 & 0.141 & 22 & 81.3 & 0.134 \\
\hline Virginia....... & 18 & 79.1 & 0.047 & 18 & 76.8 & 0.069 & 23 & 81.3 & 0.063 \\
\hline Florida $\ldots \ldots \ldots \ldots \ldots$ & 19 & 79.0 & 0.032 & 22 & 76.3 & 0.047 & 13 & 81.8 & 0.042 \\
\hline lowa................ & 20 & 79.0 & 0.077 & 19 & 76.5 & 0.113 & 16 & 81.6 & 0.101 \\
\hline Illinois & 21 & 79.0 & 0.039 & 20 & 76.4 & 0.058 & 19 & 81.5 & 0.052 \\
\hline United States . & & 78.8 & & & 76.3 & & . & 81.4 & \\
\hline Arizona...... & 22 & 78.8 & 0.054 & 25 & 76.1 & 0.080 & 15 & 81.6 & 0.071 \\
\hline North Dakota . & 23 & 78.8 & 0.166 & 21 & 76.3 & 0.235 & 21 & 81.5 & 0.227 \\
\hline Texas ...... & 24 & 78.6 & 0.026 & 24 & 76.1 & 0.038 & 25 & 81.0 & 0.035 \\
\hline Maryland . & 25 & 78.5 & 0.059 & 30 & 75.8 & 0.088 & 24 & 81.2 & 0.075 \\
\hline Montana............. & 26 & 78.4 & 0.139 & 23 & 76.2 & 0.204 & 31 & 80.8 & 0.185 \\
\hline South Dakota . . . . . . . . . & 27 & 78.4 & 0.157 & 26 & 76.1 & 0.226 & 29 & 80.8 & 0.214 \\
\hline Pennsylvania ........... & 28 & 78.3 & 0.040 & 31 & 75.7 & 0.059 & 27 & 80.9 & 0.053 \\
\hline Maine............... & 29 & 78.3 & 0.123 & 28 & 75.8 & 0.180 & 28 & 80.9 & 0.164 \\
\hline Kansas ................ & 30 & 78.2 & 0.082 & 27 & 75.9 & 0.119 & 34 & 80.4 & 0.111 \\
\hline Delaware & 31 & 78.1 & 0.153 & 35 & 75.1 & 0.225 & 26 & 81.0 & 0.202 \\
\hline District of Columbia...... & 32 & 78.0 & 0.186 & 37 & 74.9 & 0.276 & 30 & 80.8 & 0.244 \\
\hline Nevada.............. & 33 & 78.0 & 0.080 & 33 & 75.6 & 0.115 & 32 & 80.6 & 0.107 \\
\hline Michigan $\ldots \ldots \ldots \ldots \ldots$ & 34 & 78.0 & 0.045 & 32 & 75.6 & 0.066 & 35 & 80.3 & 0.060 \\
\hline Alaska ............... & 35 & 77.7 & 0.173 & 29 & 75.8 & 0.247 & 38 & 79.9 & 0.237 \\
\hline Wyoming ..... & 36 & 77.7 & 0.199 & 34 & 75.4 & 0.279 & 33 & 80.5 & 0.262 \\
\hline North Carolina .......... & 37 & 77.6 & 0.045 & 36 & 75.0 & 0.066 & 36 & 80.1 & 0.059 \\
\hline Georgia $\ldots \ldots \ldots \ldots \ldots$ & 38 & 77.4 & 0.044 & 38 & 74.9 & 0.065 & 39 & 79.9 & 0.059 \\
\hline Indiana.............. & 39 & 77.0 & 0.056 & 39 & 74.5 & 0.081 & 42 & 79.5 & 0.075 \\
\hline Missouri. .............. & 40 & 76.9 & 0.059 & 41 & 74.1 & 0.087 & 40 & 79.8 & 0.078 \\
\hline New Mexico ........... & 41 & 76.9 & 0.109 & 42 & 73.9 & 0.159 & 37 & 80.1 & 0.143 \\
\hline Ohio . & 42 & 76.9 & 0.043 & 40 & 74.3 & 0.062 & 43 & 79.5 & 0.057 \\
\hline South Carolina .......... & 43 & 76.8 & 0.066 & 43 & 73.9 & 0.098 & 41 & 79.7 & 0.086 \\
\hline Louisiana . . . . . . . . . . . . . & 44 & 75.7 & 0.070 & 47 & 72.8 & 0.102 & 44 & 78.6 & 0.093 \\
\hline Oklahoma............. & 45 & 75.7 & 0.073 & 44 & 73.2 & 0.106 & 47 & 78.3 & 0.099 \\
\hline Arkansas ............. & 46 & 75.7 & 0.085 & 45 & 73.0 & 0.122 & 46 & 78.4 & 0.114 \\
\hline Tennessee $\ldots \ldots \ldots \ldots$ & 47 & 75.6 & 0.057 & 48 & 72.8 & 0.082 & 45 & 78.5 & 0.075 \\
\hline Kentucky ............ & 48 & 75.5 & 0.068 & 46 & 72.9 & 0.097 & 49 & 78.0 & 0.091 \\
\hline Alabama............. & 49 & 75.2 & 0.068 & 49 & 72.2 & 0.099 & 48 & 78.2 & 0.090 \\
\hline West Virginia $\ldots \ldots \ldots \ldots$ & 50 & 74.5 & 0.114 & 50 & 71.9 & 0.164 & 51 & 77.3 & 0.153 \\
\hline Mississippi. ........... & 51 & 74.4 & 0.089 & 51 & 71.2 & 0.129 & 50 & 77.6 & 0.118 \\
\hline
\end{tabular}

... Category not applicable.

NOTE: Life expectancies shown are rounded, but rankings are based on unrounded life expectancies.

SOURCE: National Center for Health Statistics, National Vital Statistics System, Mortality. 
males, with a life expectancy of 78.4 years. Mississippi ranked 51st among the 50 states and D.C. for the total and male populations, with life expectancies at birth of 74.4 and 71.2 years, respectively. West Virginia ranked 51st among females, with a life expectancy at birth of 77.3 years. In comparison, life expectancy at birth for the entire United States was 78.8, 76.3, and 81.4 for the total, male, and female populations, respectively. Figure 1 presents a U.S. map with state-specific life expectancy at birth grouped into quartiles. It shows that states with the lowest life expectancy at birth are mostly Southern states, and states with the highest life expectancy at birth are predominantly Western and Northeastern states.

The difference in life expectancy between the sexes in the United States was 5.1 years in 2019, ranging from a high of 6.4 years in Mississippi to a low of 3.5 years in Utah (Figure 2). With a few exceptions, the states with the largest sex differences are those with lower life expectancy at birth, while the smallest sex differences are found mostly among states with higher life expectancy.

Table B shows life expectancy at age 65 for the total, male, and female populations for the 50 states, D.C., and United States. In 2019, Hawaii ranked first for the total, male, and female populations, with life expectancy at age 65 of 21.2, 19.4, and 22.9 years, respectively. Mississippi ranked 51 st, with the lowest life expectancy among the 50 states and D.C. for the total and male populations, with life expectancy at age 65 of 17.5 and 15.8 years, respectively. For females, Kentucky ranked 51 st, with a life expectancy at age 65 of 18.8 years. In comparison, life expectancy at age 65 for the entire United States was 19.6, 18.2, and 20.8 for the total, male, and female populations, respectively. Figure 3 shows that states with the lowest life expectancies at age 65 are mostly concentrated in the South, and those with the highest life expectancies are mostly in the West and Northeast.

From 2018 to 2019, life expectancy at birth declined for 14 states (Figure 4) (5). The declines ranged from 0.1 to 0.5 year. Life expectancy remained the same for 5 states and increased for 31 states and D.C. Increases ranged from 0.1 to 0.5 year. Overall, life expectancy in the United States increased by 0.1 year from 2018 to 2019.

\section{References}

1. Arias E, Xu JQ. United States life tables, 2018. National Vital Statistics Reports; vol 69 no 12. Hyattsville, MD: National Center for Health Statistics. 2020.

2. Shryock HS, Siegel JS, Larmon EA. The methods and materials of demography, vol 2. Washington, DC: U.S. Census Bureau. 1971.

3. Moriyama IM, Gustavus So. Cohort mortality and survivorship: United States death-registration states, 1900-1968. National Center for Health Statistics. Vital Health Stat 3(16). 1972. Available from: https://www.cdc. gov/nchs/data/series/sr_03/sr03_016.pdf.

\section{Figure 1. Life expectancy at birth: Each state, District of Columbia, and United States, 2019}

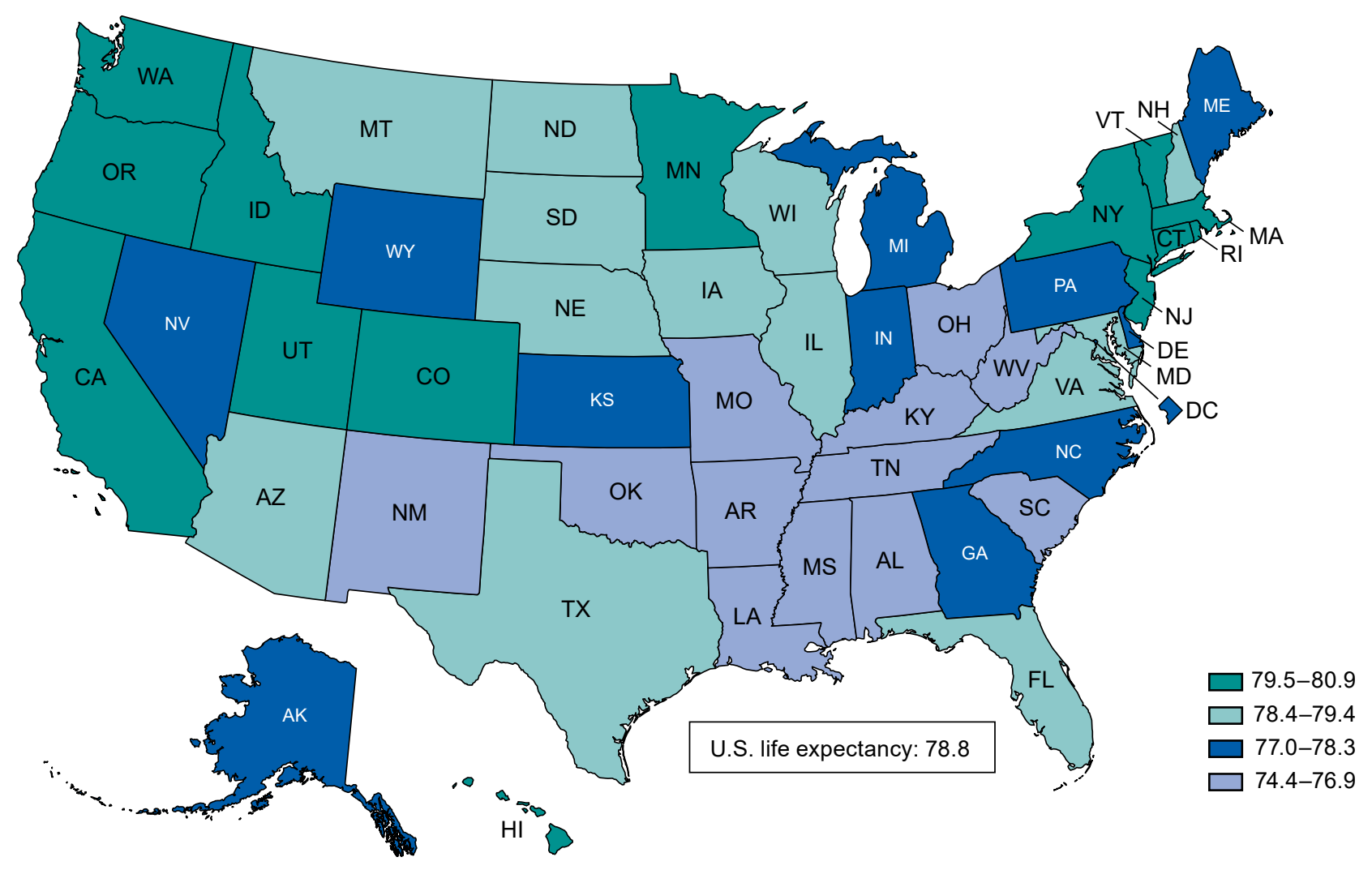

SOURCE: National Center for Health Statistics, National Vital Statistics System, Mortality 
Figure 2. Difference between male and female life expectancy at birth: Each state, District of Columbia, and United States, 2019

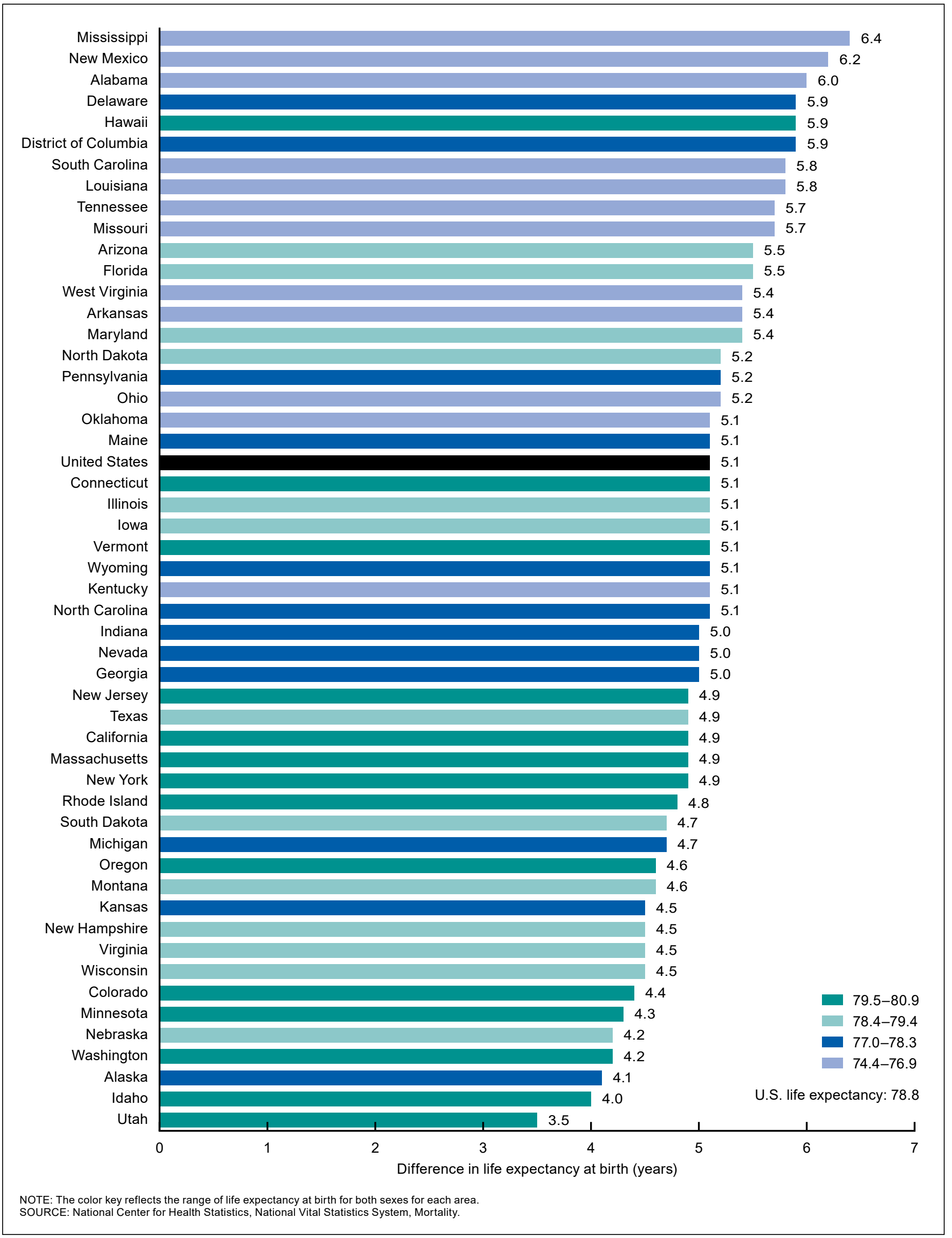


Table B. Life expectancy at age 65, rank, and standard error, by sex: Each state, District of Columbia, and United States, 2019

\begin{tabular}{|c|c|c|c|c|c|c|c|c|c|}
\hline Area & Rank & Total & Standard error & Rank & Male & Standard error & Rank & Female & Standard error \\
\hline Hawaii . & 1 & 21.2 & 0.065 & 1 & 19.4 & 0.090 & 1 & 22.9 & 0.089 \\
\hline California ... & 2 & 20.5 & 0.013 & 2 & 19.1 & 0.019 & 2 & 21.8 & 0.018 \\
\hline New York. & 3 & 20.3 & 0.018 & 4 & 18.8 & 0.025 & 3 & 21.6 & 0.024 \\
\hline Connecticut ........... & 4 & 20.2 & 0.039 & 5 & 18.8 & 0.055 & 4 & 21.5 & 0.053 \\
\hline Colorado ............. & 5 & 20.1 & 0.031 & 3 & 19.0 & 0.045 & 11 & 21.1 & 0.043 \\
\hline Florida $\ldots \ldots \ldots \ldots \ldots$ & 6 & 20.1 & 0.016 & 10 & 18.6 & 0.023 & 5 & 21.4 & 0.022 \\
\hline Massachussetts . . . . . . . . & 7 & 20.1 & 0.028 & 7 & 18.7 & 0.040 & 6 & 21.3 & 0.039 \\
\hline New Jersey ............ & 8 & 20.0 & 0.026 & 9 & 18.6 & 0.036 & 8 & 21.2 & 0.035 \\
\hline Minnesota . & 9 & 20.0 & 0.031 & 6 & 18.7 & 0.044 & 7 & 21.2 & 0.043 \\
\hline District of Columbia . . . . . . & 10 & 19.9 & 0.115 & 20 & 18.3 & 0.171 & 9 & 21.1 & 0.152 \\
\hline Vermont............. & 11 & 19.9 & 0.085 & 12 & 18.5 & 0.121 & 10 & 21.1 & 0.117 \\
\hline Arizona............... & 12 & 19.8 & 0.028 & 13 & 18.5 & 0.041 & 12 & 21.0 & 0.038 \\
\hline Washington ........... & 13 & 19.8 & 0.027 & 11 & 18.5 & 0.039 & 15 & 20.9 & 0.037 \\
\hline Delaware ............. & 14 & 19.7 & 0.071 & 23 & 18.2 & 0.103 & 13 & 21.0 & 0.095 \\
\hline Oregon............... & 15 & 19.6 & 0.035 & 14 & 18.5 & 0.050 & 19 & 20.7 & 0.048 \\
\hline New Mexico . . . . . . . . . . . & 16 & 19.6 & 0.051 & 19 & 18.3 & 0.074 & 16 & 20.8 & 0.068 \\
\hline United States . . . . . . . . . & $\ldots$ & 19.6 & & $\ldots$ & 18.2 & $\ldots$ & $\ldots$ & 20.8 & \\
\hline Utah............... & 17 & 19.6 & 0.047 & 8 & 18.6 & 0.067 & 28 & 20.5 & 0.065 \\
\hline South Dakota... & 18 & 19.6 & 0.077 & 18 & 18.3 & 0.107 & 17 & 20.8 & 0.108 \\
\hline Rhode Island. & 19 & 19.6 & 0.071 & 21 & 18.2 & 0.101 & 20 & 20.7 & 0.097 \\
\hline New Hampshire ......... . & 20 & 19.5 & 0.058 & 15 & 18.4 & 0.081 & 25 & 20.6 & 0.081 \\
\hline North Dakota ........... & 21 & 19.5 & 0.090 & 28 & 18.0 & 0.122 & 14 & 20.9 & 0.127 \\
\hline Idaho ....... & 22 & 19.5 & 0.055 & 17 & 18.3 & 0.077 & 27 & 20.5 & 0.076 \\
\hline Maryland ............. & 23 & 19.5 & 0.032 & 24 & 18.1 & 0.045 & 22 & 20.6 & 0.043 \\
\hline Wisconsin ........... & 24 & 19.5 & 0.030 & 25 & 18.1 & 0.041 & 18 & 20.7 & 0.042 \\
\hline Illinois ....... & 25 & 19.4 & 0.022 & 26 & 18.0 & 0.031 & 21 & 20.6 & 0.030 \\
\hline Nebraska . . . . . . . . . . & 26 & 19.4 & 0.055 & 27 & 18.0 & 0.077 & 23 & 20.6 & 0.076 \\
\hline Virginia.............. & 27 & 19.3 & 0.026 & 29 & 18.0 & 0.038 & 26 & 20.5 & 0.036 \\
\hline lowa.... & 28 & 19.3 & 0.042 & 30 & 17.9 & 0.059 & 24 & 20.6 & 0.058 \\
\hline Montana. . & 29 & 19.3 & 0.065 & 22 & 18.2 & 0.091 & 30 & 20.4 & 0.091 \\
\hline Pennsylvania . & 30 & 19.3 & 0.020 & 31 & 17.9 & 0.028 & 29 & 20.5 & 0.028 \\
\hline Alaska ....... & 31 & 19.2 & 0.090 & 16 & 18.4 & 0.127 & 35 & 20.1 & 0.126 \\
\hline Maine............... & 32 & 19.1 & 0.056 & 32 & 17.8 & 0.080 & 32 & 20.3 & 0.077 \\
\hline Wyoming ........... & 33 & 19.1 & 0.091 & 33 & 17.8 & 0.124 & 31 & 20.4 & 0.130 \\
\hline Texas ................. & 34 & 19.0 & 0.016 & 35 & 17.7 & 0.022 & 33 & 20.2 & 0.021 \\
\hline Michigan ............. & 35 & 18.9 & 0.023 & 34 & 17.7 & 0.033 & 37 & 20.0 & 0.032 \\
\hline Kansas ................ & 36 & 18.9 & 0.045 & 36 & 17.6 & 0.062 & 34 & 20.1 & 0.062 \\
\hline South Carolina .......... & 37 & 18.8 & 0.032 & 37 & 17.4 & 0.047 & 38 & 20.0 & 0.043 \\
\hline North Carolina ......... . & 38 & 18.8 & 0.023 & 38 & 17.4 & 0.033 & 39 & 19.9 & 0.031 \\
\hline Nevada...... & 39 & 18.7 & 0.044 & 39 & 17.4 & 0.062 & 36 & 20.1 & 0.060 \\
\hline Missouri. . & 40 & 18.6 & 0.030 & 40 & 17.2 & 0.043 & 40 & 19.8 & 0.042 \\
\hline Georgia . . & 41 & 18.6 & 0.025 & 42 & 17.2 & 0.035 & 41 & 19.8 & 0.033 \\
\hline Ohio ............... & 42 & 18.5 & 0.022 & 41 & 17.2 & 0.030 & 42 & 19.7 & 0.030 \\
\hline Indiana .............. & 43 & 18.4 & 0.029 & 43 & 17.0 & 0.041 & 43 & 19.6 & 0.041 \\
\hline Louisiana . . . . . . . . . . . . . & 44 & 18.2 & 0.035 & 44 & 16.8 & 0.050 & 44 & 19.5 & 0.049 \\
\hline Tennessee ............ & 45 & 18.0 & 0.029 & 45 & 16.5 & 0.041 & 45 & 19.3 & 0.039 \\
\hline Arkansas .............. & 46 & 17.8 & 0.044 & 48 & 16.3 & 0.062 & 46 & 19.2 & 0.060 \\
\hline Oklahoma.............. & 47 & 17.8 & 0.039 & 46 & 16.5 & 0.055 & 49 & 18.9 & 0.054 \\
\hline Alabama... & 48 & 17.7 & 0.034 & 50 & 16.2 & 0.048 & 47 & 19.1 & 0.046 \\
\hline West Virginia . & 49 & 17.7 & 0.051 & 47 & 16.4 & 0.071 & 50 & 18.9 & 0.071 \\
\hline Kentucky ... & 50 & 17.7 & 0.035 & 49 & 16.3 & 0.049 & 51 & 18.8 & 0.048 \\
\hline Mississippi. . . . . . . . . . & 51 & 17.5 & 0.044 & 51 & 15.8 & 0.063 & 48 & 19.0 & 0.061 \\
\hline
\end{tabular}

... Category not applicable.

NOTE: Life expectancies shown are rounded, but rankings are based on unrounded life expectancies.

SOURCE: National Center for Health Statistics, National Vital Statistics System, Mortality. 
Figure 3. Life expectancy at age 65: Each state, District of Columbia, and United States, 2019

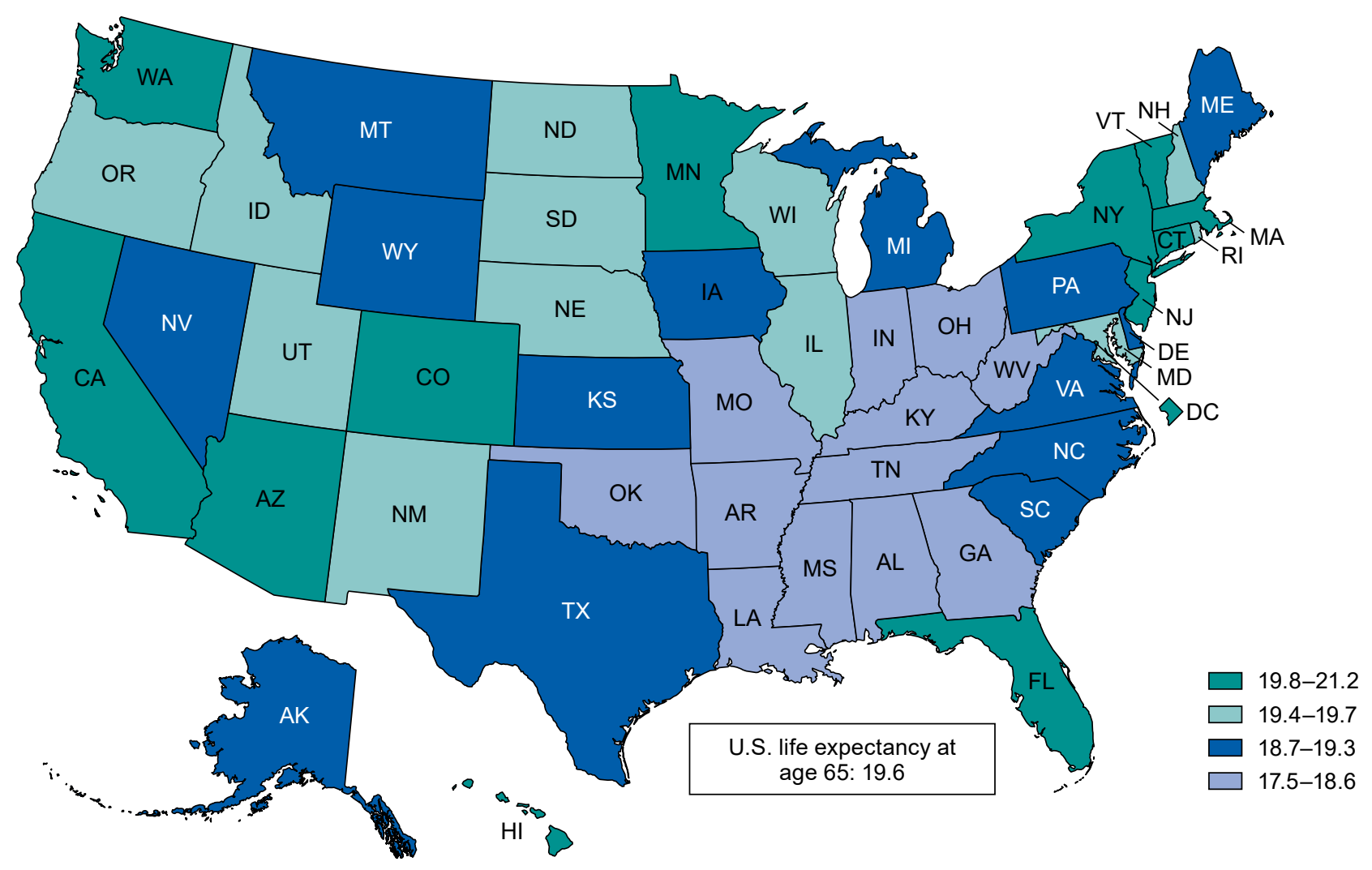

Figure 4. Change in life expectancy at birth from 2018 to 2019: Each state and District of Columbia

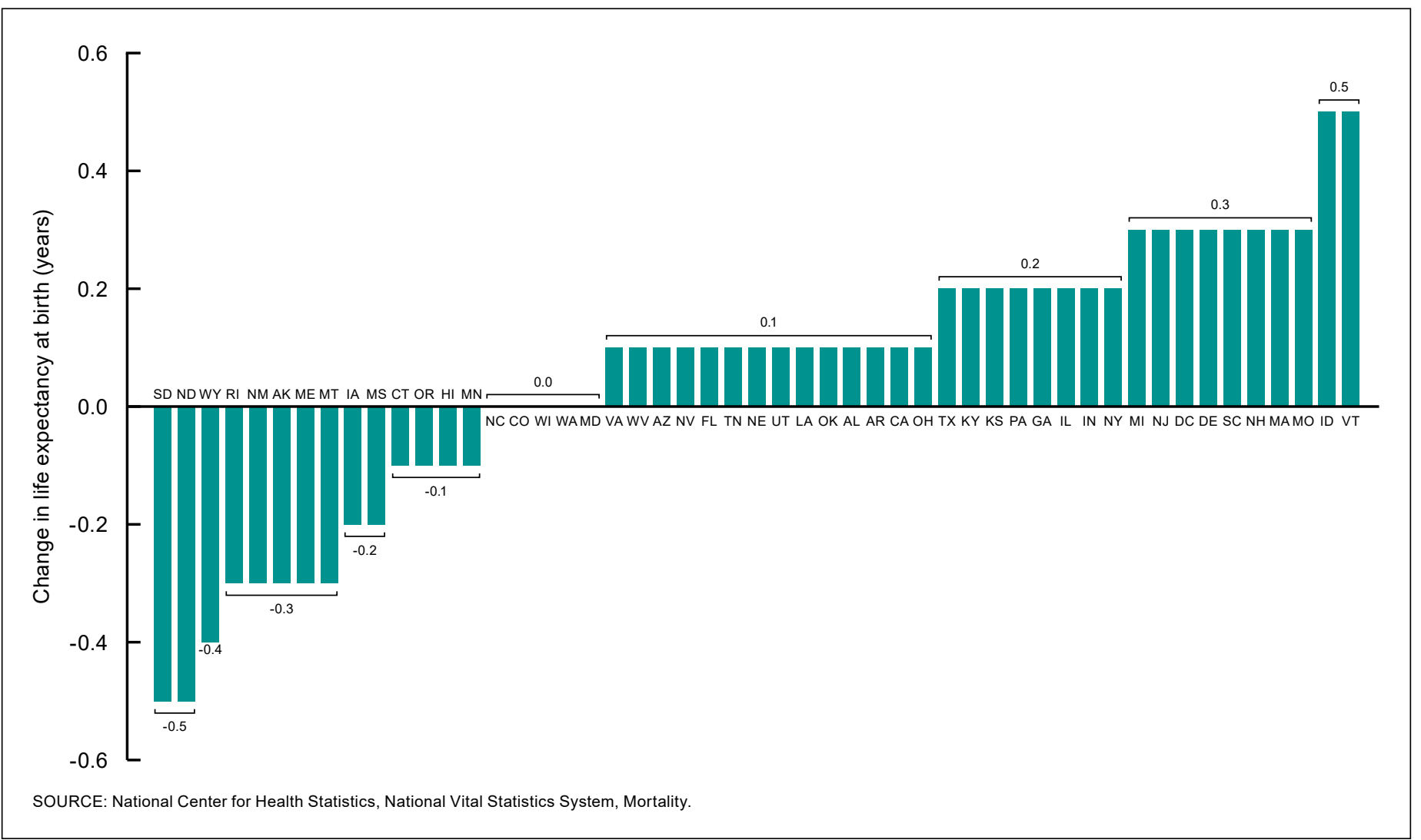


4. Preston SH, Heuveline P, Guillot M. Demography: Measuring and modeling population processes. Oxford: Blackwell Publishers. 2001.

5. Arias E, Bastian B, Xu JQ, Tejada-Vera B. U.S. state life tables, 2018. National Vital Statistics Reports; vol 70 no 1. Hyattsville, MD: National Center for Health Statistics. 2021. DOI: https://doi.org/10.15620/cdc:101128.

6. Bell FC, Miller ML. Life tables for the United States Social Security area 1900-2100. Actuarial Study No. 120. SSA Pub. No. 11-11536. Baltimore, MD: Social Security Administration. 2005.

7. Anderson RN. Method for constructing complete annual U.S. life tables. National Center for Health Statistics. Vital Health Stat 2(129). 1999. Available from: https://www.cdc. gov/nchs/data/series/sr_02/sr02_129.pdf.

8. Thatcher AR, Kannisto V, Vaupel JW. The force of mortality at ages 80 to 120 . Odense, Denmark: Odense University Press. 1998.

9. Andreev KF, Bourbeau RR. Frailty modeling of Canadian and Swedish mortality at adult and advanced ages. In: Population Association of America Annual Meeting program. Silver Spring, MD. 2007.

10. Chiang CL. The life table and its applications. Malabar, FL: Robert E. Krieger Publishing Company, Inc. 1984.

11. Arias E, Curtin SC, Tejada-Vera B. U.S. decennial life tables for 2009-2011: Methodology of the United States life tables. National Vital Statistics Reports; vol 69 no 10. Hyattsville, MD: National Center for Health Statistics. 2020.

12. Silcocks PB, Jenner DA, Reza R. Life expectancy as a summary of mortality in a population: Statistical considerations and suitability for use by health authorities. J Epidemiol Community Health 55(1):38-43. 2001. 


\section{Technical Notes}

The methods used to estimate the 2019 complete life tables for the 50 states and the District of Columbia (D.C.) are the same as those used to estimate the U.S. annual life tables, with two modifications (1). First, for states with zero death counts at single ages 1-4 years, linear interpolation was used to replace those zero death counts. For a few states, linear interpolation was also used to replace zero and negative death counts resulting from the application of Beers' smoothing technique to very small death counts for ages 6-12 years. Second, a modification was made to the estimation of the age-specific death rates for ages 66-99. Because state age-specific census population estimates for ages 85-100 are not available, the age range needed to be modified where vital and Medicare death rates are blended and where Medicare data are used exclusively. Details of the methodology and modifications follow.

\section{Data for calculating life table functions}

The data used to prepare the U.S. state life tables (Table I) include state-specific final death counts from the National Vital Statistics System (NVSS), state-specific population estimates from the U.S. Census Bureau, and state-specific death and population counts for Medicare beneficiaries aged 66-99 from the Centers for Medicare \& Medicaid Services (CMS).

\section{Vital statistics data}

Death counts used for computing the life tables presented in this report are state-specific final numbers of deaths for 2019 collected from death certificates filed in state vital statistics offices and reported to the National Center for Health Statistics (NCHS) as part of NVSS.

\section{Census population data}

The population data used to estimate the life tables shown in this report are state-specific postcensal population estimates based on the 2010 decennial census and are available from the Census Bureau website at: https://www2.census.gov/programssurveys/popest/tables/2010-2019/state/asrh/sc-est2019alldata6.csv.

\section{Medicare data}

Data from the Medicare program are used to supplement vital statistics and census data for ages 66-99 for the total population and by sex for each state and D.C.

Medicare data are considered more accurate than vital statistics and census data at the oldest ages because Medicare enrollees must have proof of age to enroll (6). However, the reliability of Medicare data beyond age 100 declines because of the small percentage of people who enrolled at the start of the Medicare program in 1965 for whom it was not possible to verify exact age (6).

\section{Table I. Complete period life tables: $\mathbf{5 0}$ states and District of Columbia, 2019}

Available from: https://ftp.cdc.gov/pub/Health_Statistics/NCHS/Publications/ NVSR/70-18/

\section{Table title}

AK-1. Life table for total population: Alaska, 2019

AK-2. Life table for males: Alaska, 2019

AK-3. Life table for females: Alaska, 2019

AK-4. Standard errors of probability of dying and life expectancy: Alaska, 2019

$\mathrm{AL}-1$. Life table for total population: Alabama, 2019

AL-2. Life table for males: Alabama, 2019

AL-3. Life table for females: Alabama, 2019

$A L-4$. Standard errors of probability of dying and life expectancy: Alabama, 2019

AR-1. Life table for total population: Arkansas, 2019

AR-2. Life table for males: Arkansas, 2019

AR-3. Life table for females: Arkansas, 2019

AR-4. Standard errors of probability of dying and life expectancy: Arkansas, 2019

AZ-1. Life table for total population: Arizona, 2019

AZ-2. Life table for males: Arizona, 2019

AZ-3. Life table for females: Arizona, 2019

AZ-4. Standard errors of probability of dying and life expectancy: Arizona, 2019

CA-1. Life table for total population: California, 2019

CA-2. Life table for males: California, 2019

CA-3. Life table for females: California, 2019

CA-4. Standard errors of probability of dying and life expectancy: California, 2019

C0-1. Life table for total population: Colorado, 2019

CO-2. Life table for males: Colorado, 2019

CO-3. Life table for females: Colorado, 2019

CO-4. Standard errors of probability of dying and life expectancy: Colorado, 2019

CT-1. Life table for total population: Connecticut, 2019

CT-2. Life table for males: Connecticut, 2019

CT-3. Life table for females: Connecticut, 2019

CT-4. Standard errors of probability of dying and life expectancy: Connecticut, 2019

DC-1. Life table for total population: District of Columbia, 2019

DC-2. Life table for males: District of Columbia, 2019

DC-3. Life table for females: District of Columbia, 2019

DC-4. Standard errors of probability of dying and life expectancy: District of Columbia, 2019

DE-1. Life table for total population: Delaware, 2019

DE-2. Life table for males: Delaware, 2019

DE-3. Life table for females: Delaware, 2019

$D E-4$. Standard errors of probability of dying and life expectancy: Delaware, 2019

FL-1. Life table for total population: Florida, 2019

FL-2. Life table for males: Florida, 2019

FL-3. Life table for females: Florida, 2019

FL-4. Standard errors of probability of dying and life expectancy: Florida, 2019

GA-1. Life table for total population: Georgia, 2019

GA-2. Life table for males: Georgia, 2019

GA-3. Life table for females: Georgia, 2019

$\mathrm{GA}-4$. Standard errors of probability of dying and life expectancy: Georgia, 2019

HI-1. Life table for total population: Hawaii, 2019

HI-2. Life table for males: Hawaii, 2019

HI-3. Life table for females: Hawaii, 2019

$\mathrm{HI}-4$. Standard errors of probability of dying and life expectancy: Hawaii, 2019

$\mid A-1$. Life table for total population: lowa, 2019

IA-2. Life table for males: lowa, 2019

IA-3. Life table for females: Iowa, 2019

IA-4. Standard errors of probability of dying and life expectancy: Iowa, 2019

ID-1. Life table for total population: Idaho, 2019

ID-2. Life table for males: Idaho, 2019

ID-3. Life table for females: Idaho, 2019

See footnote at end of table. 
Table I. Complete period life tables: $\mathbf{5 0}$ states and District of Columbia, 2019-Con.

Available from: https://ftp.cdc.gov/pub/Health_Statistics/NCHS/Publications/NVSR/70-18/

Table title

ID-4. Standard errors of probability of dying and life expectancy: Idaho, 2019

IL-1. Life table for total population: Illinois, 2019

IL-2. Life table for males: Illinois, 2019

IL-3. Life table for females: Illinois, 2019

IL-4. Standard errors of probability of dying and life expectancy: Illinois, 2019

IN-1. Life table for total population: Indiana, 2019

IN-2. Life table for males: Indiana, 2019

IN-3. Life table for females: Indiana, 2019

IN-4. Standard errors of probability of dying and life expectancy: Indiana, 2019

KS-1. Life table for total population: Kansas, 2019

KS-2. Life table for males: Kansas, 2019

KS-3. Life table for females: Kansas, 2019

KS-4. Standard errors of probability of dying and life expectancy: Kansas, 2019

KY-1. Life table for total population: Kentucky, 2019

KY-2. Life table for males: Kentucky, 2019

KY-3. Life table for females: Kentucky, 2019

KY-4. Standard errors of probability of dying and life expectancy: Kentucky, 2019

LA-1. Life table for total population: Louisiana, 2019

LA-2. Life table for males: Louisiana, 2019

LA-3. Life table for females: Louisiana, 2019

LA-4. Standard errors of probability of dying and life expectancy: Louisiana, 2019

MA-1. Life table for total population: Massachusetts, 2019

MA-2. Life table for males: Massachusetts, 2019

MA-3. Life table for females: Massachusetts, 2019

MA-4. Standard errors of probability of dying and life expectancy: Massachusetts, 2019

MD-1. Life table for total population: Maryland, 2019

MD-2. Life table for males: Maryland, 2019

MD-3. Life table for females: Maryland, 2019

MD-4. Standard errors of probability of dying and life expectancy: Maryland, 2019

ME-1. Life table for total population: Maine, 2019

ME-2. Life table for males: Maine, 2019

ME-3. Life table for females: Maine, 2019

ME-4. Standard errors of probability of dying and life expectancy: Maine, 2019

MI-1. Life table for total population: Michigan, 2019

MI-2. Life table for males: Michigan, 2019

MI-3. Life table for females: Michigan, 2019

$\mathrm{MI}-4$. Standard errors of probability of dying and life expectancy: Michigan, 2019

MN-1. Life table for total population: Minnesota, 2019

MN-2. Life table for males: Minnesota, 2019

MN-3. Life table for females: Minnesota, 2019

MN-4. Standard errors of probability of dying and life expectancy: Minnesota, 2019

M0-1. Life table for total population: Missouri, 2019

M0-2. Life table for males: Missouri, 2019

MO-3. Life table for females: Missouri, 2019

M0-4. Standard errors of probability of dying and life expectancy: Missouri, 2019

MS-1. Life table for total population: Mississippi, 2019

MS-2. Life table for males: Mississippi, 2019

MS-3. Life table for females: Mississippi, 2019

MS-4. Standard errors of probability of dying and life expectancy: Mississippi, 2019

MT-1. Life table for total population: Montana, 2019

MT-2. Life table for males: Montana, 2019

MT-3. Life table for females: Montana, 2019

MT-4. Standard errors of probability of dying and life expectancy: Montana, 2019

NC-1. Life table for total population: North Carolina, 2019

See footnote at end of table.
Table title

NC-2. Life table for males: North Carolina, 2019

NC-3. Life table for females: North Carolina, 2019

NC-4. Standard errors of probability of dying and life expectancy: North Carolina, 2019

ND-1. Life table for total population: North Dakota, 2019

ND-2. Life table for males: North Dakota, 2019

ND-3. Life table for females: North Dakota, 2019

ND-4. Standard errors of probability of dying and life expectancy: North Dakota, 2019

NE-1. Life table for total population: Nebraska, 2019

NE-2. Life table for males: Nebraska, 2019

NE-3. Life table for females: Nebraska, 2019

$\mathrm{NE}-4$. Standard errors of probability of dying and life expectancy: Nebraska, 2019

$\mathrm{NH}-1$. Life table for total population: New Hampshire, 2019

NH-2. Life table for males: New Hampshire, 2019

$\mathrm{NH}-3$. Life table for females: New Hampshire, 2019

$\mathrm{NH}-4$. Standard errors of probability of dying and life expectancy: New Hampshire, 2019

NJ-1. Life table for total population: New Jersey, 2019

NJ-2. Life table for males: New Jersey, 2019

NJ-3. Life table for females: New Jersey, 2019

NJ-4. Standard errors of probability of dying and life expectancy: New Jersey, 2019

NM-1. Life table for total population: New Mexico, 2019

NM-2. Life table for males: New Mexico, 2019

NM-3. Life table for females: New Mexico, 2019

NM-4. Standard errors of probability of dying and life expectancy: New Mexico, 2019

NV-1. Life table for total population: Nevada, 2019

NV-2. Life table for males: Nevada, 2019

NV-3. Life table for females: Nevada, 2019

NV-4. Standard errors of probability of dying and life expectancy: Nevada, 2019

NY-1. Life table for total population: New York, 2019

NY-2. Life table for males: New York, 2019

NY-3. Life table for females: New York, 2019

NY-4. Standard errors of probability of dying and life expectancy: New York, 2019

$\mathrm{OH}-1$. Life table for total population: Ohio, 2019

OH-2. Life table for males: Ohio, 2019

$\mathrm{OH}-3$. Life table for females: Ohio, 2019

$\mathrm{OH}-4$. Standard errors of probability of dying and life expectancy: Ohio, 2019

OK-1. Life table for total population: Oklahoma, 2019

OK-2. Life table for males: Oklahoma, 2019

OK-3. Life table for females: Oklahoma, 2019

OK-4. Standard errors of probability of dying and life expectancy: Oklahoma, 2019

OR-1. Life table for total population: Oregon, 2019

OR-2. Life table for males: Oregon, 2019

OR-3. Life table for females: Oregon, 2019

OR-4. Standard errors of probability of dying and life expectancy: Oregon, 2019

PA-1. Life table for total population: Pennsylvania, 2019

PA-2. Life table for males: Pennsylvania, 2019

PA-3. Life table for females: Pennsylvania, 2019

PA-4. Standard errors of probability of dying and life expectancy: Pennsylvania, 2019

RI-1. Life table for total population: Rhode Island, 2019

RI-2. Life table for males: Rhode Island, 2019

RI-3. Life table for females: Rhode Island, 2019

RI-4. Standard errors of probability of dying and life expectancy: Rhode Island, 2019

SC-1. Life table for total population: South Carolina, 2019

SC-2. Life table for males: South Carolina, 2019 
Table I. Complete period life tables: $\mathbf{5 0}$ states and District of Columbia, 2019-Con.

Available from: https://ftp.cdc.gov/pub/Health_Statistics/NCHS/Publications/ NVSR/70-18/

Table title

SC-3. Life table for females: South Carolina, 2019

SC-4. Standard errors of probability of dying and life expectancy: South Carolina, 2019

SD-1. Life table for total population: South Dakota, 2019

SD-2. Life table for males: South Dakota, 2019

SD-3. Life table for females: South Dakota, 2019

SD-4. Standard errors of probability of dying and life expectancy: South Dakota, 2019

TN-1. Life table for total population: Tennessee, 2019

TN-2. Life table for males: Tennessee, 2019

TN-3. Life table for females: Tennessee, 2019

TN-4. Standard errors of probability of dying and life expectancy: Tennessee, 2019

TX-1. Life table for total population: Texas, 2019

TX-2. Life table for males: Texas, 2019

TX-3. Life table for females: Texas, 2019

TX-4. Standard errors of probability of dying and life expectancy: Texas, 2019

UT-1. Life table for total population: Utah, 2019

UT-2. Life table for males: Utah, 2019

UT-3. Life table for females: Utah, 2019

UT-4. Standard errors of probability of dying and life expectancy: Utah, 2019

VA-1. Life table for total population: Virginia, 2019

VA-2. Life table for males: Virginia, 2019

VA-3. Life table for females: Virginia, 2019

VA-4. Standard errors of probability of dying and life expectancy: Virginia, 2019

VT-1. Life table for total population: Vermont, 2019

VT-2. Life table for males: Vermont, 2019

VT-3. Life table for females: Vermont, 2019

VT-4. Standard errors of probability of dying and life expectancy: Vermont, 2019

WA-1. Life table for total population: Washington, 2019

WA-2. Life table for males: Washington, 2019

WA-3. Life table for females: Washington, 2019

WA-4. Standard errors of probability of dying and life expectancy: Washington, 2019

WI-1. Life table for total population: Wisconsin, 2019

WI-2. Life table for males: Wisconsin, 2019

WI-3. Life table for females: Wisconsin, 2019

WI-4. Standard errors of probability of dying and life expectancy: Wisconsin, 2019

WV-1. Life table for total population: West Virginia, 2019

WV-2. Life table for males: West Virginia, 2019

WV-3. Life table for females: West Virginia, 2019

WV-4. Standard errors of probability of dying and life expectancy: West Virginia, 2019

WY-1. Life table for total population: Wyoming, 2019

WY-2. Life table for males: Wyoming, 2019

WY-3. Life table for females: Wyoming, 2019

WY-4. Standard errors of probability of dying and life expectancy: Wyoming, 2019

SOURCE: National Center for Health Statistics, National Vital Statistics System, Mortality.
To estimate death rates for the state-specific Medicare populations in 2019, sex- and age-specific numbers of deaths and population counts were used for the population aged 66-99 in each state and D.C. from the 2019 Medicare file. The data file, created by CMS for the Social Security Administration, is shared with NCHS under a special agreement. The 2019 file contains state-specific 2019 midyear Medicare population counts (as of June 30, 2019) and calendar-year Medicare death counts (for January 1 through December 31, 2019). Age for both death and midyear population counts is calculated as age at last birthday.

\section{Preliminary adjustment of data}

\section{Adjustments for unknown age}

An adjustment is made to account for the small proportion of deaths each year for which age is not reported on the death certificate. The number of deaths in each age category is adjusted proportionally to account for those with not-stated age. An adjustment factor $(F)$ is used to distribute deaths with nonstated ages. $F$ is calculated for the total population and by sex for each state and D.C. as:

$$
F=\frac{D}{D^{a}}
$$

where $D$ is the total number of deaths and $D^{a}$ is the total number of deaths for which age is stated. $F$ is then applied by multiplying it by the number of deaths in each age group.

\section{Interpolation of $\boldsymbol{P}_{\boldsymbol{X}}$ and $\boldsymbol{D}_{\boldsymbol{X}}$}

Anomalies-both random and those associated with reporting age at death - can be problematic when using vital statistics and census data by single years of age to estimate the probability of death $(2,7)$. Graduation techniques are often used to eliminate these anomalies and to derive a smooth curve by age. Beers' ordinary minimized fifth difference formula is used to obtain smoothed values of population counts $\left(P_{x}\right)$ and death counts $\left(D_{x}\right)$ from 5-year age groupings of ${ }_{n} P_{x}$ from age 0-99 and ${ }_{n} D_{x}$ from age 5-99, and where ${ }_{n} D_{x}$ has first been adjusted for notreported age on the death certificate (see reference 7 for details on the application of Beers' method). Beers' interpolation is not applied to deaths at ages $0-4$.

For states with zero death counts in the age range 1-4 years, those counts needed to be replaced using linear interpolation; otherwise, zero death counts would have resulted in the discontinuation of the age-specific mortality distribution. In a few other cases, application of Beers' interpolation of deaths in the age range $6-12$ resulted in zero or negative death counts because of very small numbers of deaths, so linear interpolation was also applied. The assumption of linearity is warranted because mortality declines somewhat linearly between ages 1 and 10 or so, and the results led to smooth age patterns of mortality (see Table II for a list of states and ages where linear interpolation was used). 
Table II. Application of linear interpolation for selected states, by sex and age

\begin{tabular}{|c|c|c|}
\hline \multirow[b]{2}{*}{ Area } & \multicolumn{2}{|c|}{ Age (years) } \\
\hline & Male & Female \\
\hline Connecticut . & & 3 \\
\hline Delaware . & $4,10,11$ & 3 \\
\hline District of Columbia. & 2,4 & 4 \\
\hline Hawaii .......... & 4 & .. \\
\hline Idaho .... . & $\ldots$ & 4 \\
\hline$\ldots \ldots \ldots \ldots \ldots \ldots \ldots$ & $\ldots$ & 3 \\
\hline$\ldots \ldots \ldots \ldots \ldots \ldots \ldots$ & $\ldots$ & 3 \\
\hline$\ldots \ldots \ldots \ldots$ & 4 & $\ldots$ \\
\hline$\ldots \ldots \ldots \ldots$ & 3 & 2,3 \\
\hline$\ldots \ldots \ldots \ldots$ & 4 & 2,4 \\
\hline$\ldots \ldots \ldots \ldots$ & $\ldots$ & 2 \\
\hline New Hampshire. & 2 & $4,6,7$ \\
\hline New Mexico.... & $\ldots$ & 4 \\
\hline North Dakota . & & 2,3 \\
\hline$\ldots \ldots \ldots \ldots \ldots$ & 4 & $\ldots$ \\
\hline Rhode Island. & & 2,3 \\
\hline South Dakota. & $3,10,11$ & $\ldots$ \\
\hline$\ldots \ldots \ldots \ldots \ldots \ldots \ldots$ & 3 & 3 \\
\hline West Virginia $\ldots \ldots \ldots \ldots \ldots \ldots \ldots \ldots \ldots$ & $\ldots$ & 11,12 \\
\hline 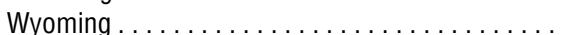 & 3 & 1,2 \\
\hline
\end{tabular}

Category not applicable.

SOURCE: National Center for Health Statistics, National Vital Statistics System, Mortality.

\section{Calculation of probability of dying $\left(q_{x}\right)$}

The first step in the calculation of a complete period life table is the estimation of the age-specific probability of dying, $q_{x}$, which is derived from the age-specific death rate, $m_{x}(2,4)$. In the life table cohort,

$$
m_{x}=\frac{d_{x}}{L_{x}}
$$

where $d_{x}$ is the number of deaths occurring between ages $x$ and $x+1$, and $L_{x}$ is the number of person-years lived by the life table cohort between ages $x$ and $x+1$. The conversion of the agespecific death rate, $m_{x}$, to the age-specific probability of death, $q_{x}$, is:

$$
q_{x}=\frac{m_{x}}{1+\left(1-a_{x}\right) m_{x}}
$$

where $a_{x}$ is the number of person-years lived in the age interval by members of the life table cohort who died in the interval. When the age interval is 1 year, except at infancy, $a_{x}=1 / 2$; in other words, deaths occur on average midway through the age interval. As a result,

$$
q_{x}=\frac{m_{x}}{1+\frac{1}{2} m_{x}}
$$

Because the complete period life table is based on the age-specific death rates of a current population observed for a specific calendar year, the life table death rate is equivalent to the observed death rate of the current population:

$$
m_{x}=\frac{d_{x}}{L_{x}}=M_{x}=\frac{D_{x}}{P_{x}}
$$

where $D_{x}$ is the Beers' smoothed (or linearly interpolated) number of deaths adjusted for not-stated age and $P_{x}$ is the Beers' smoothed population at risk of dying between ages $x$ and $x+1$. Then,

$$
q_{x}=\frac{M_{x}}{1+\frac{1}{2} M_{x}}=\frac{D_{x}}{P_{x}+\frac{1}{2} D_{x}}
$$

This procedure is used to estimate vital statistics age-specific probabilities of death for ages 1-84.

\section{Calculation of $q_{x}$ at age 0}

The higher mortality observed in infancy is associated with a high concentration of deaths occurring at the beginning of the age interval rather than in the middle. As a result, assigning deaths to the appropriate birth cohorts is best whenever possible. Therefore, the probability of death at birth, $q_{0}$, is calculated using a birth cohort method that uses a separation factor $(f)$ defined as the proportion of infant deaths in year $t$ occurring to infants born in the previous year $(t-1)$. The value $f$ is estimated by categorizing infant deaths by date of birth. The probability of death is then calculated as:

$$
q_{0}=\frac{D_{0}(1-f)}{B^{t}}+\frac{D_{0}(f)}{B^{t-1}}
$$

where $D_{0}$ is the number of infant deaths adjusted for not-stated age in $2019, B^{t}$ is the number of live births in 2019 , and $B^{t-1}$ is the number of live births in 2018.

\section{Probabilities of dying at oldest ages}

Medicare data are used to supplement vital statistics data for the estimation of $q_{\mathrm{x}}$ at the oldest ages because these data are more accurate, given that proof of age is required for enrollment in the Medicare program. Medicare data are used here to estimate the probability of dying for ages 66-99.

For this method, these steps are followed: First, vital statistics and Medicare death rates are blended in the age range 66-99. Second, a logistic model is used to smooth the blended death rates in the age range 85-99 and to predict death rates for ages $100-120$. Third, final resulting death rates, $M_{x}$, are converted to probabilities of dying, $q_{x}$.

For the national life tables, vital statistics, $M_{x}^{V}$, and Medicare, $M_{x}{ }^{M}$, death rates are blended in the age range 66-94 with a weighting process that gives gradually declining weight to vital statistics data and gradually increasing weight to Medicare data. For ages $95-99, M_{x}{ }^{M}$ is used exclusively. Due to the unavailability of census state population estimates for ages $85-100$, calculating $M_{x}^{V}$ for this age span is not possible. 
As a result, the blending technique was modified such that $M_{x}{ }^{V}$ and $M_{x}{ }^{M}$ are blended in the age range 66-84 and $M_{x}{ }^{M}$ is used exclusively in the age range $85-99$. Blended $M_{x}$ is thus obtained as:

$$
M_{x}=\frac{1}{20}\left[(85-x) M_{x}^{V}+(x-65) M_{x}^{M}\right]
$$

when $x=66, \ldots, 84$, and

$$
M_{x}=M_{x}^{M}
$$

when $x=85, \ldots, 99$.

$M_{x}{ }^{M}$ is estimated as:

$$
M_{x}^{M}=\frac{D_{x}^{M}}{P_{x}^{M}}
$$

where $D_{x}^{M}$ is the age-specific Medicare death count, and $P_{x}^{M}$ is the age-specific Medicare midyear population count.

The exclusive use of Medicare death rates beginning at age 85 for the state life tables is expected to have a negligible biasing effect on mortality at older ages in the life tables compared with the national life tables. As Figures I-III show, while large differences are found between Medicare and vital statistics death rates at ages 85 and over for the U.S. population, blended Medicare and vital statistics death rates are very similar to Medicare death rates for ages 85 and over.

A logistic model proposed by Kannisto is then used to smooth $M_{x}$ in the age range 85-99 and predict $M_{x}$ in the age range 100-120 (8). The start of the modeled age range varies by sex because it is a function of the age at which the rate of change in the age-specific death rates peaks. In current times, the rate of change in the age-specific death rate rises steadily up to about ages $80-85$ and then begins to decline. As a result, modeling a large age span such as $65-100$ with one simple model is difficult without oversmoothing and thus altering the underlying mortality pattern observed in the population of interest (9). Further, the observed data for the age range $65-85$ or so is reliable and robust, as indicated by the very close similarity between vital statistics and Medicare death rates, making it unnecessary to model, or smooth, the entire age span (65-100).

The Kannisto model is a simple form of a logistic model in which the logit of $u_{x}$ (or the natural log of the odds of $u_{x}$ ) is a linear function of age $x(8)$. It is expressed as:

$$
\ln \left[\frac{u_{x}}{1-u_{x}}\right]=\ln (\alpha)+\beta x
$$

where $u_{x}$, the force of mortality (or the instantaneous death rate), is defined as:

$$
u_{x}=\frac{\alpha e^{\beta x}}{1+\alpha e^{\beta x}}
$$

Because $u_{x}$ is not directly observed but is closely approximated by $m_{x}$, and $m_{x}=M_{x}$, then the logit of $M_{x}$ is modeled instead. A maximum-likelihood generalized linear model estimation procedure is used to fit the following model in the age range 85-99:

$$
\ln \left[\frac{M_{x}}{1-M_{x}}\right]=\ln (\alpha)+\beta x
$$

Figure I. Age-specific vital statistics, Medicare, and blended death rates for total population: United States, 2019

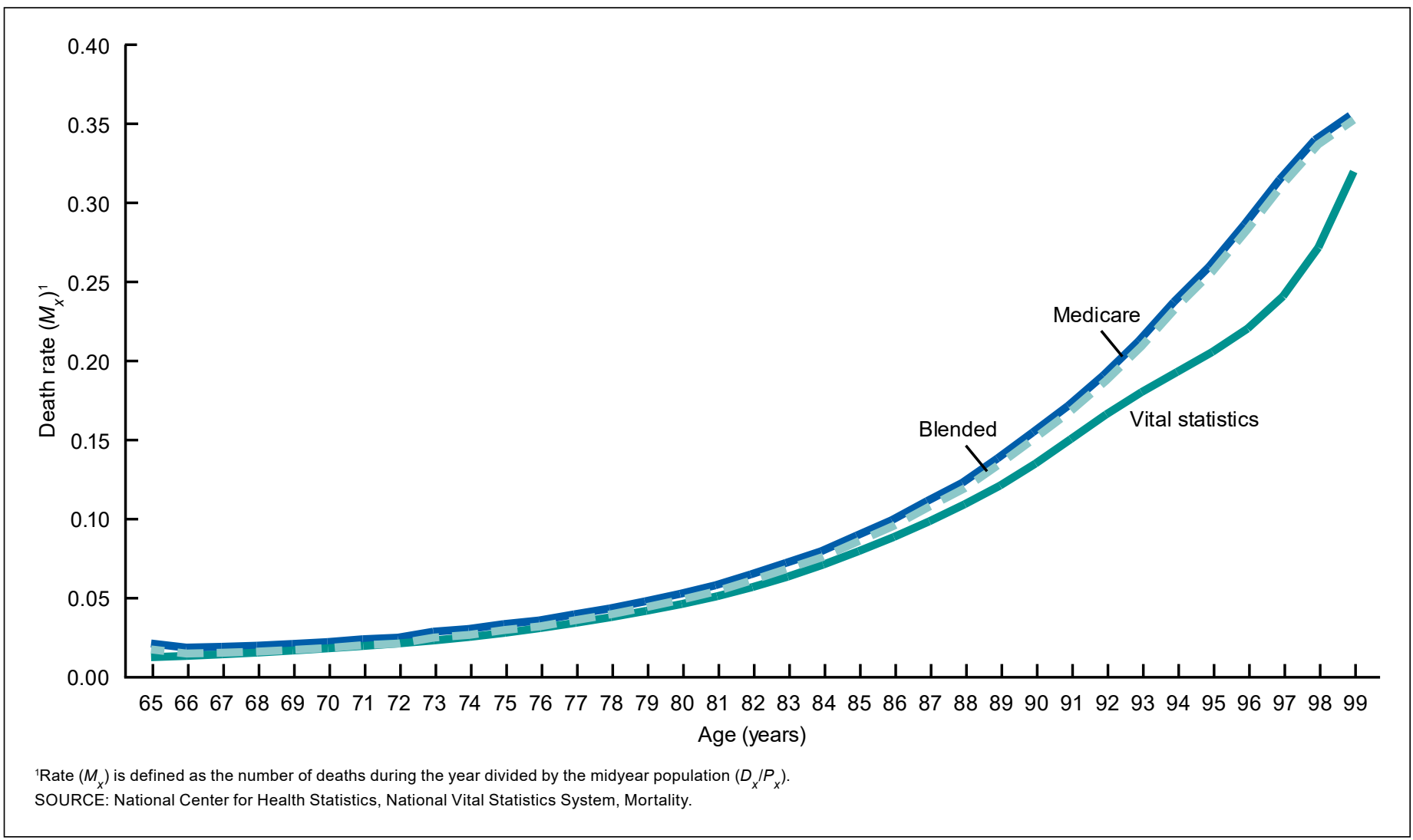


Figure II. Age-specific vital statistics, Medicare, and blended death rates for male population: United States, 2019

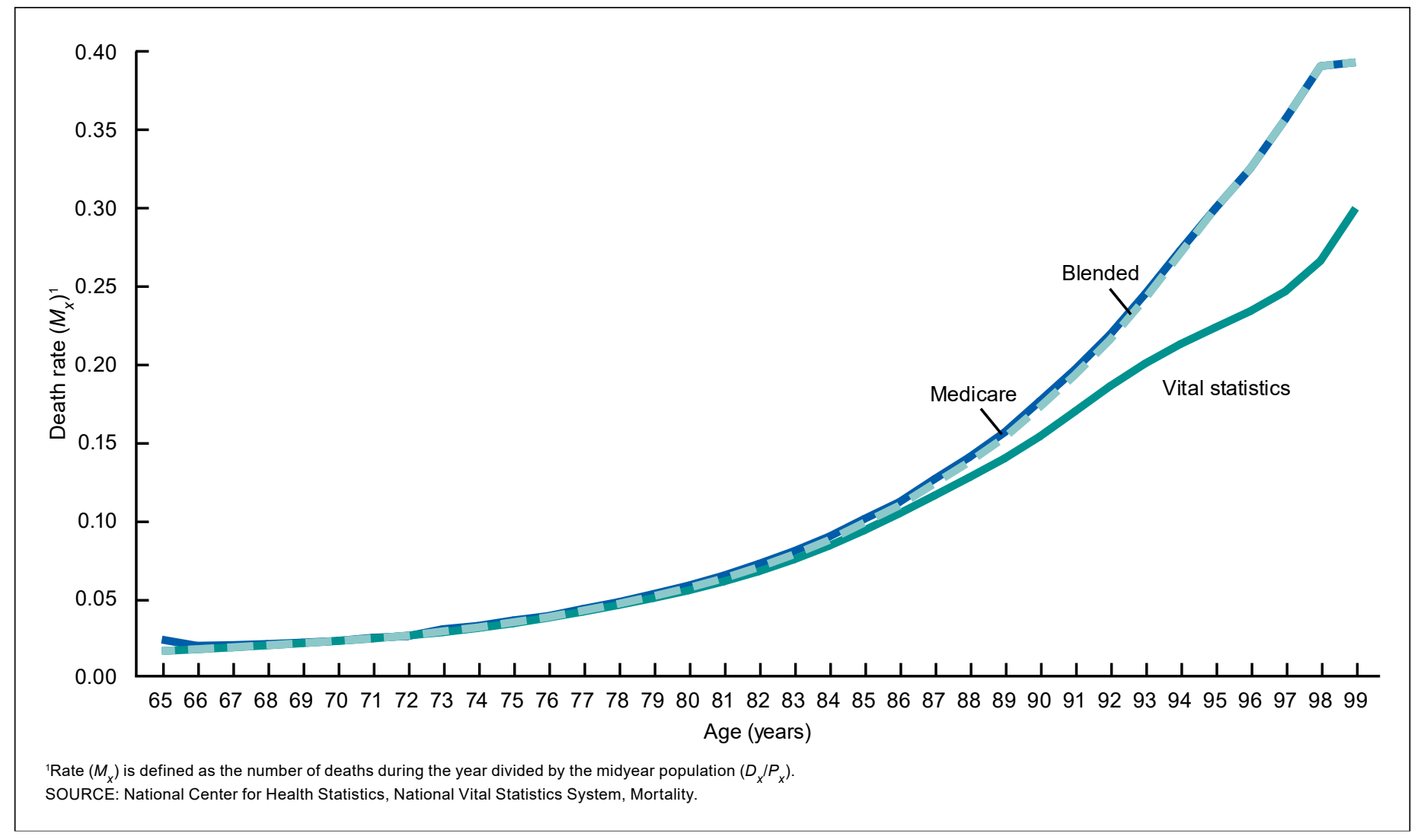

Figure III. Age-specific vital statistics, Medicare, and blended death rates for female population: United States, 2019

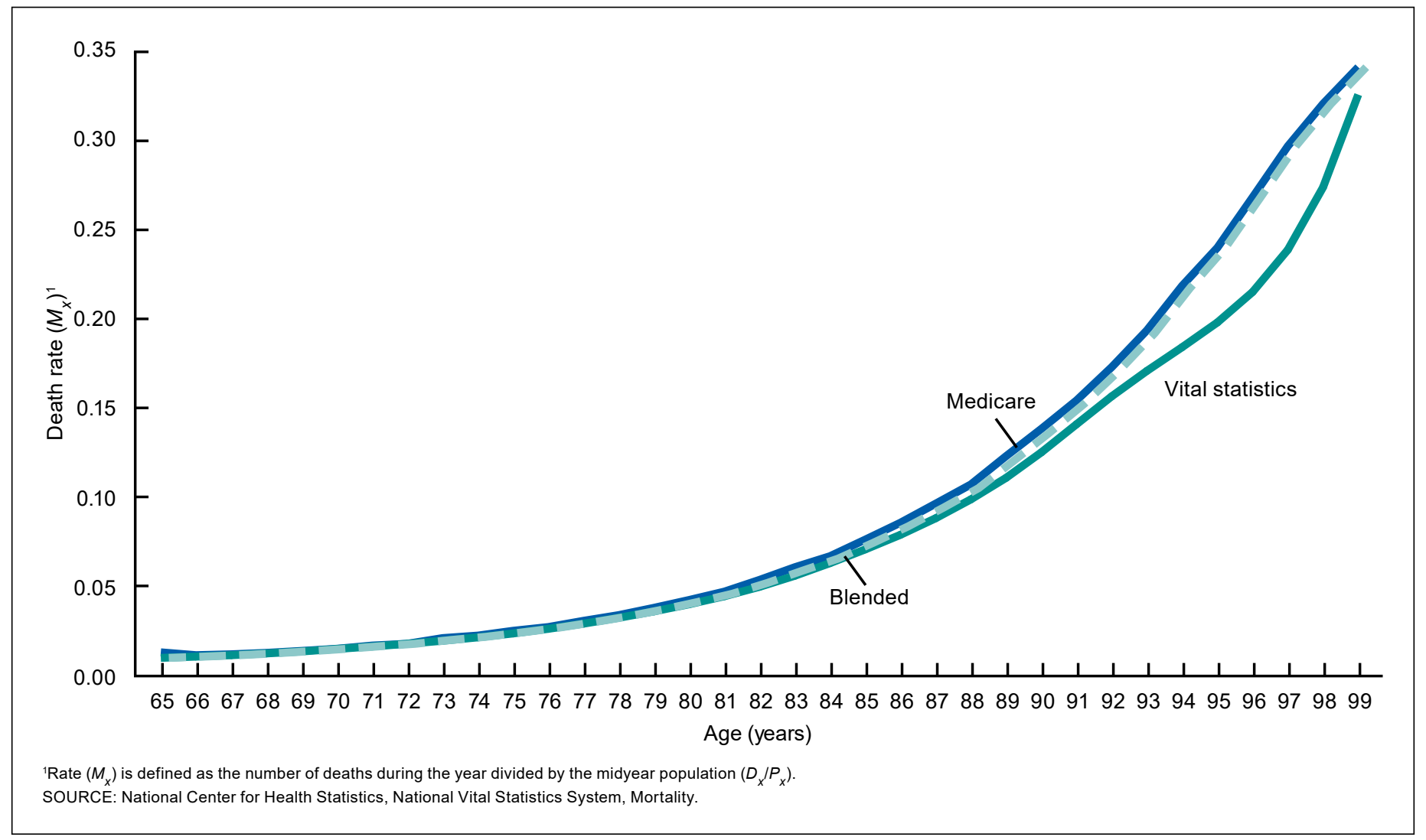


Then, the estimated parameters are used to predict $\bar{M}_{x}$ as:

$$
\bar{M}_{x}=\frac{e^{a} e^{b x}}{1+e^{a} e^{b x}} \text { or, equivalently, } \bar{M}_{x}=\frac{e^{a+b x}}{1+e^{a+b x}}
$$

where $a$ and $b$ are the predicted values of parameters $\ln (\alpha)$ and $\beta$, respectively, given by fitting model [8].

Finally, the predicted probability of death, $q_{x}$, for ages $85-120$ is estimated by converting $\bar{M}_{x}$ as:

$$
\bar{q}_{x}=\frac{\bar{M}_{x}}{1+\frac{1}{2} \bar{M}_{x}}
$$

The probability of death is extrapolated to age 120 to estimate the life table population until no survivors remain. This information is then used to estimate $L_{x}$ for ages $100-120$, which is used to close the table with the age category 100 and over, combined (see following discussion).

Figures IV-VI show the age-specific probability of dying, $q_{\mathrm{x}}$, estimates for each of the 50 states and D.C. compared with the values for the United States in 2019. The observed probabilities for the states and D.C. are shown as circles, which appear as vertical bars where they overlap, and the U.S. probabilities are shown as an intersecting connected line. The state estimates fall about the U.S. values as expected, with a few outliers in the youngest childhood ages. These few cases are predominantly the result of a very small number of deaths, consistent with very low mortality in this age range, combined with very small populations in states such as Vermont, Wyoming, and North Dakota. Overall, age-specific estimates for the 50 states and D.C. follow the expected age pattern of mortality and are consistent with the mortality pattern observed for the entire United States.

\section{Calculation of remaining life table functions for all groups \\ Survivor function $\left(I_{x}\right)$}

The life table radix, $I_{0}$, is set at 100,000 . For ages over 0 , the number of survivors remaining at exact age $x$ is calculated as:

$$
I_{x}=I_{x-1}\left(1-q_{x-1}\right)
$$

\section{Decrement function $\left(d_{x}\right)$}

The number of deaths occurring between ages $x$ and $x+1$ is calculated from the survivor function:

$$
d_{x}=I_{x}-I_{x-1}=I_{x} q_{x}
$$

Note that ${ }_{\infty} d_{100}={ }_{\infty} I_{100}$ because ${ }_{\infty} q_{100}=1.0$.

Figure IV. Age patterns of mortality for states and District of Columbia compared with United States, 2019

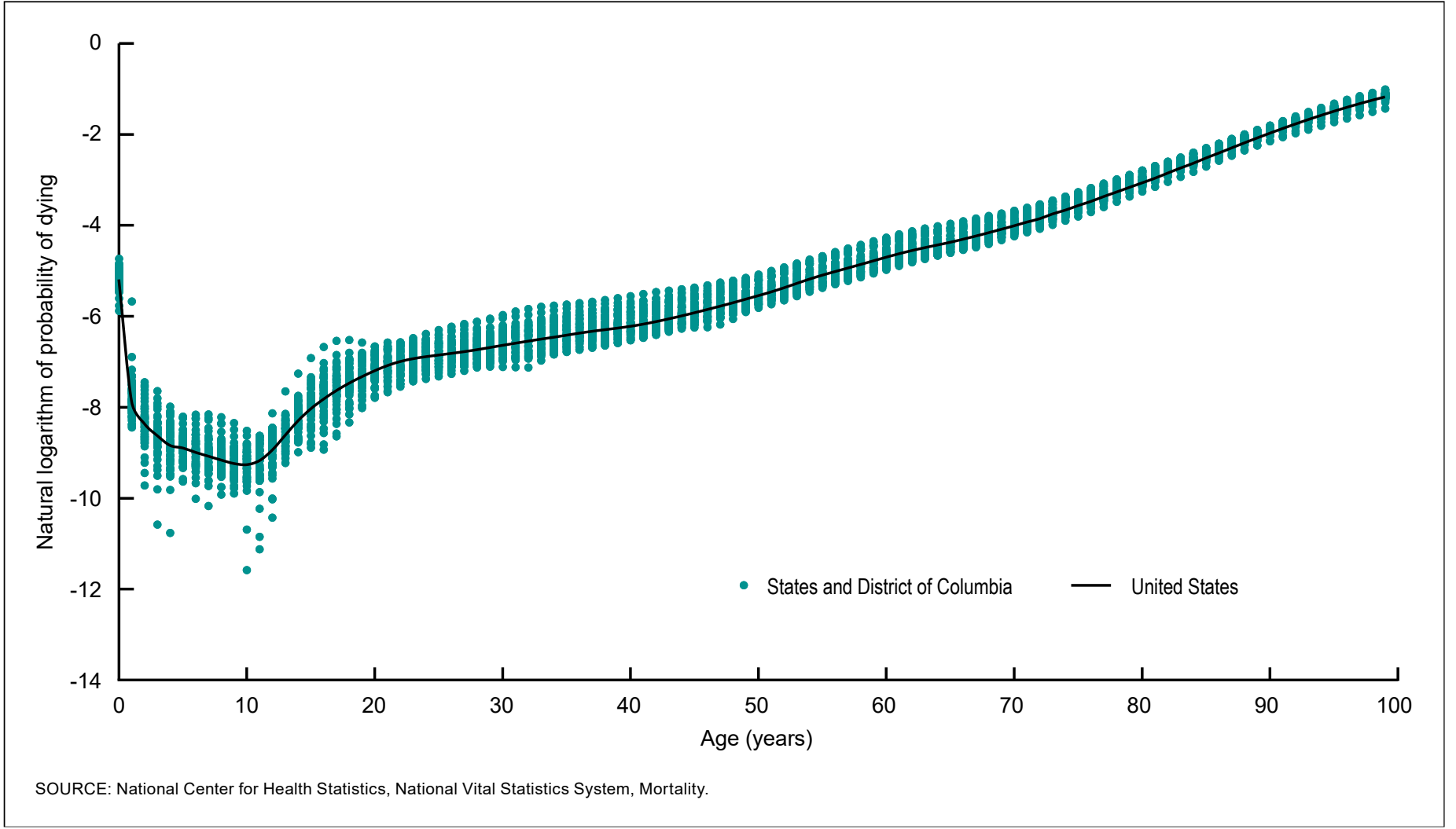


Figure V. Male age patterns of mortality for states and District of Columbia compared with United States, 2019

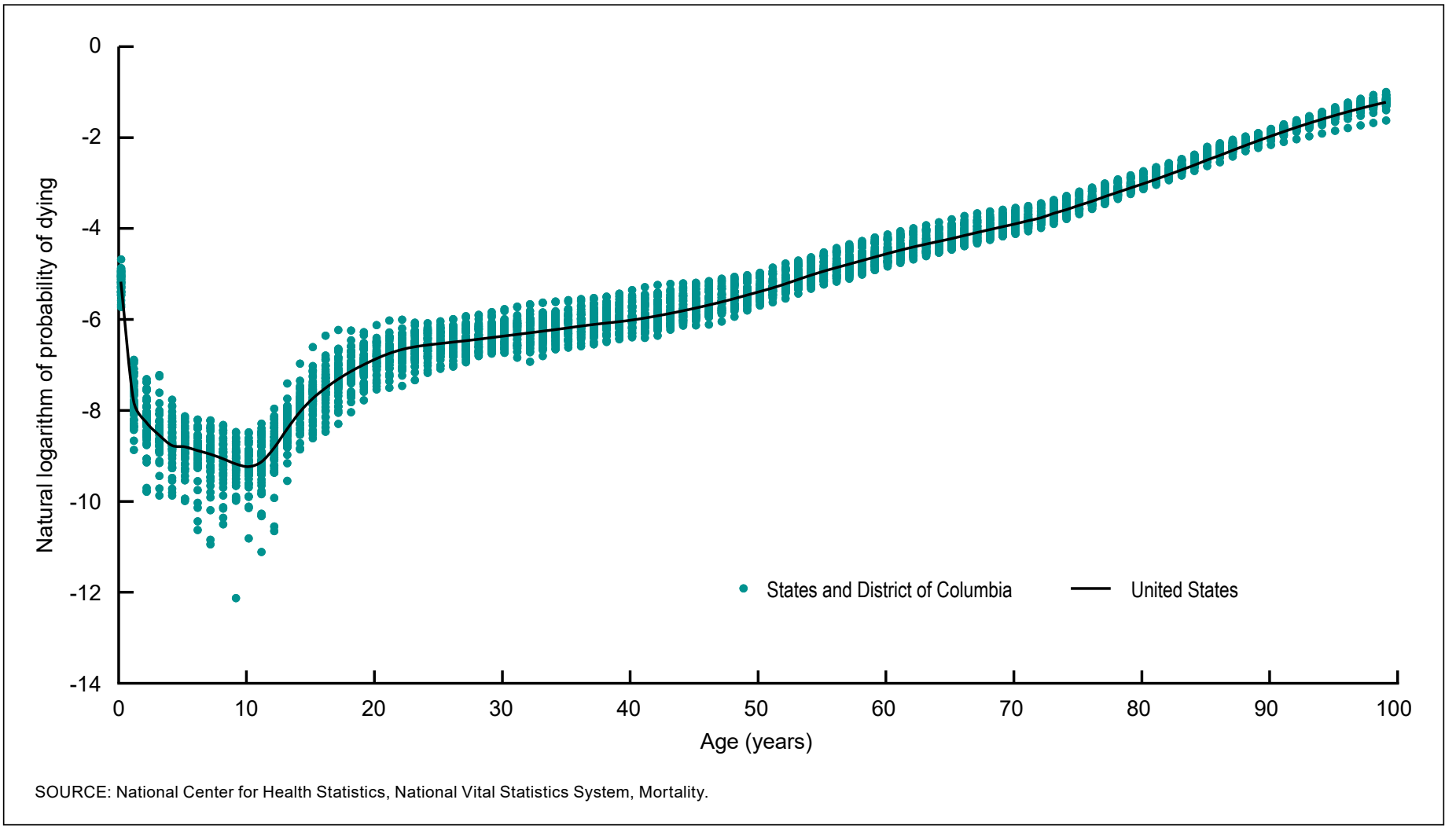

Figure VI. Female age patterns of mortality for states and District of Columbia compared with United States, 2019

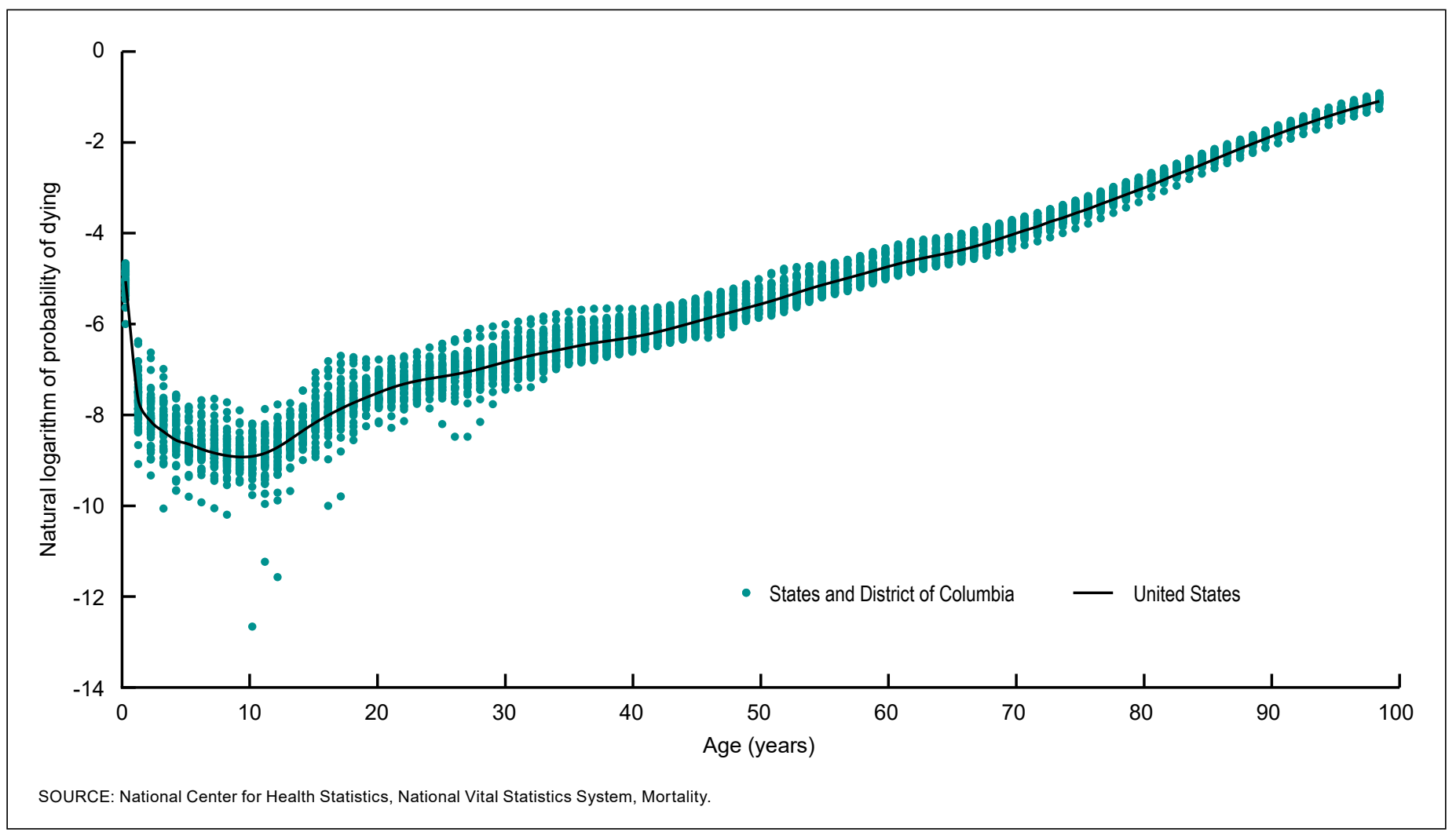




\section{Person-years lived $\left(L_{x}\right)$}

Person-years lived for ages 1-99 are calculated assuming that the survivor function declines linearly between ages $x$ and $x+1$. This gives the formula:

$$
L_{x}=\frac{1}{2}\left(I_{x}+I_{x+1}\right)=I_{x}-\frac{1}{2} d_{x}
$$

For $x=0$, the separation factor $f$ is used to calculate $L_{0}$ :

$$
L_{0}=f I_{0}+(1-f) I_{1}
$$

Finally, ${ }_{\infty} L_{100}$ is estimated as the sum of the extrapolated $L_{x}$ values for ages 100-120.

\section{Person-years lived at age $x$ and over $\left(T_{x}\right)$}

$T_{x}$ is calculated by summing $L_{x}$ values at age $x$ and over:

$$
T_{x}=\sum_{x=0}^{\infty} L_{x}
$$

\section{Life expectancy at age $x\left(e_{x}\right)$}

Life expectancy at exact age $x$ is calculated as:

$$
e_{x}=\frac{T_{x}}{I_{x}}
$$

\section{Variances and standard errors of the probability of dying and life expectancy}

The mortality data on which the life tables are based are not affected by sampling error because the data are based on complete counts of deaths, and, as a result, variances and standard errors reflect only random variation. While measurement errors such as age misreporting are known to affect mortality estimates, they are not considered in the calculation of the variances or standard errors of the life table functions. Because the state life tables presented in this report are based on relatively large numbers of deaths, the variances and standard errors presented are rather small.

The methods used to estimate the variances of $q_{x}$ and $e_{x}$ are based on Chiang (10) with some necessary modifications due to the use of statistical modeling for smoothing and prediction of older-age death rates. Based on the assumption that deaths are binomially distributed, Chiang proposed the following equation for the variance of $q_{x}$ :

$$
\operatorname{Var}\left(q_{x}\right)=\frac{q_{x}^{2}\left(1-q_{x}\right)}{D_{x}}
$$

where $D_{x}$ is the age-specific number of deaths. This equation is used to estimate $\operatorname{Var}\left(q_{x}\right)$ throughout the age span with a modification where, for ages under age $66, D_{x}$ is the deaths from vital statistics data, smoothed by interpolation and adjusted for the number of deaths with age not stated.
For ages 66 and over, $D_{x}$ is obtained by treating the population as a cohort population and calculated from $q_{x}$ because blended vital statistics and Medicare data were used for estimation (11):

$$
\begin{gathered}
P_{x}=\frac{\left(P_{x-1}-0.5 D_{x-1}\right)\left(2-q_{x}\right)}{2} \\
D_{x}=\frac{q_{x} P_{x}}{1-0.5 q_{x}}
\end{gathered}
$$

\section{Standard error of $q_{x}$}

$$
S E\left(q_{x}\right)=\sqrt{\operatorname{Var}\left(q_{x}\right)}
$$

Variances of the life expectancies for ages 0-99 are estimated using Chiang's equation:

$$
\operatorname{Var}\left(e_{x}\right)=\frac{\sum_{x=0}^{x=99} I_{x}^{2} \bullet\left[(1-0.5)+e_{x}\right]^{2} \bullet \operatorname{Var}\left(q_{x}\right)}{l_{x}^{2}}
$$

Chiang assumed that because $q_{100+}=1.00$, then $\operatorname{Var}\left(q_{100_{+}}\right)=0$, and therefore $\operatorname{Var}\left(e_{100_{+}}\right)=0$. Silcocks et al. proposed that in the final age group, life expectancy is dependent on the mean length of survival and not on the probability of survival, and, therefore, the assumption of no variance is incorrect, and $\operatorname{Var}\left(e_{100+}\right)$ can be approximated as (12):

$$
\operatorname{Var}\left(e_{100+}\right) \approx \frac{l_{100+}^{2}}{M_{100+}^{4}} \cdot \operatorname{Var}\left(M_{100+}\right)
$$

\section{Standard error of $e_{x}$}

$$
S E\left(e_{x}\right)=\sqrt{\operatorname{Var}\left(e_{x}\right)}
$$




\section{U.S. DEPARTMENT OF \\ HEALTH \& HUMAN SERVICES}

FIRST CLASS MAIL

POSTAGE \& FEES PAID

$\mathrm{CDC} / \mathrm{NCHS}$

Centers for Disease Control and Prevention

PERMIT NO. G-284

National Center for Health Statistics

3311 Toledo Road, Room 4551

Hyattsville, MD 20782-2064

OFFICIAL BUSINESS

PENALTY FOR PRIVATE USE, $\$ 300$

For more NCHS NVSRs, visit:

https://www.cdc.gov/nchs/products/nvsr.htm.

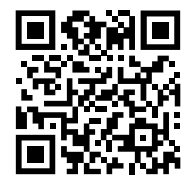

National Vital Statistics Reports, Vol. 70, No. 18, February 10, 2022

\section{Contents}

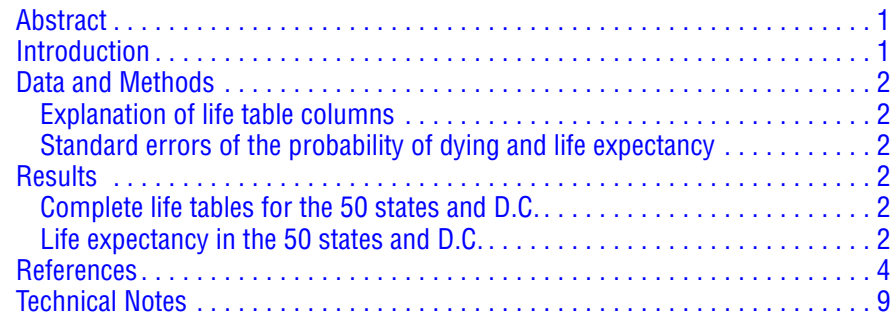

\section{Acknowledgments}

The authors are grateful for the reviews and comments provided by Robert N. Anderson, Mortality Statistics Branch (MSB), Division of Vital Statistics (DVS); Isabelle Horon, DVS; and Amy Branum, Office of the Director. The authors thank Sherry Murphy, MSB, for content review, and Anne Driscoll, Danielle Ely, and Brady Hamilton of the Reproductive Statistics Branch for their assistance with birth data. NCHS Office of Information Services, Information Design and Publishing Staff edited and produced this report: editor Jane Sudol, typesetter Jiale Feng, and graphic designer David Parker.

\section{Suggested citation}

Arias E, Xu JQ, Tejada-Vera B, Bastian B. U.S. state life tables, 2019. National Vital Statistics Reports; vol 70 no 18. Hyattsville, MD: National Center for Health Statistics. 2022. DOI: https://dx.doi.org/10.15620/cdc:113251.

\section{Copyright information}

All material appearing in this report is in the public domain and may be reproduced or copied without permission; citation as to source, however, is appreciated.
National Center for Health Statistics

Brian C. Moyer, Ph.D., Director

Amy M. Branum, Ph.D., Associate Director for Science

Division of Vital Statistics

Steven Schwartz, Ph.D., Director Isabelle Horon, Dr.P.H., Acting Associate Director for Science

For e-mail updates on NCHS publication releases, subscribe online at: https://www.cdc.gov/nchs/email-updates.htm.

For questions or general information about NCHS: Tel: 1-800-CDC-INFO (1-800-232-4636) • TTY: 1-888-232-6348 Internet: https://www.cdc.gov/nchs • Online request form: https://www.cdc.gov/info • CS328200 